BULGARIAN ACADEMY OF SCIENCES

CYBERNETICS AND INFORMATION TECHNOLOGIES • Volume 15, No 4

Sofia • 2015

Print ISSN: 1311-9702; Online ISSN: 1314-4081

DOI: $10.1515 /$ cait-2015-0050

\title{
A Generalized Multi Criteria Decision Making Method Based on Extension of ANP by Enhancing PAIR WISE Comparison Techniques
}

\author{
Arpita Barve, N. Deepa, Chandrasekar Ravi \\ School of Information Technology \& Engineering, VIT University, Vellore, Tamil Nadu \\ Emails: arpita.barve@ymail.com deepa.rajesh@vit.ac.in chandrasekar.r@vit.ac.in
}

Abstract: A model of multi criteria decision making based on extended ANP has been provided and the existing AHP scale method is replaced by another method, in which the user has to provide fewer inputs. To check the validity of the proposed method, a sample data has been taken and an enhanced method is applied on it.

Keywords: Decision making, MCDM, AHP, pair wise comparison, ANP, operation research.

\section{Introduction}

Estimation of the effort has always been a challenge for project managers. To remain competitive in the market, new organizing and operation methods have always been used by the developers. Problems have been created by complications in business environments. Therefore, the importance of decision making is being increased. The process that results into selection of an action among several alternatives and by which the uncertainty and doubts about alternatives have been reduced, is known as decision making [16]. Decision making can be done in two ways - one is based on some facts or the information users make decisions. For example, in between $300 \%$ chance to win $\$ 40$ and $10 \%$ chance to win $\$ 20$, the first option has been selected. But mostly decisions are made by users based on their assumptions, like the persons for whom the television is mainly CID, Crime Petrol, etc., could make an opinion that the world is full of criminals only.

Decision making is being encouraged in every field in our daily lives. For example, to purchase a new bungalow, dress material, vehicle, laptop, mobile, etc., according to the needs and preferences, the best option is always being selected by the user. But the user has always been confused by the variety of the options available, since some required qualities are acquired by some options and other 
qualities by other options. The decision making process is being composed of a new branch, called Multi Criteria Decision Making (MCDM) or Multi Criteria Decision Analysis (MCDA). While making a decision, if all the criteria's are being considered at a time, then this method is termed MCDM [11].

More informed and better decisions can be taken if multiple criteria are being considered and the complex problems are being structured. The knowledge of the MCDM process has been used in several domains like Research and Development, Performance Evaluation, Quality Function Deployment Implementation, Enterprise Resource Planning (ERP), Software Selection, etc., [11]. Several methods have been proposed for MCDM like Analytic Network Process (ANP), Electre method, Analytic Hierarchy Process (AHP), Aggregated Indices Randomization Method (AIRM), Data envelopment analysis, etc., $[10,11]$. It has been proved by the previous research that AHP and ANP are more efficient and therefore their use has been increased drastically.

For better understanding of the problem and in order to find out the best suitable option, AHP has been used [7]. The outcoming priorities have been usually satisfied by the people. To compare each element with every other element and to find the preference of an element over another element, AHP is being widely used in MCDM field. The judgment which criteria is more or less important for a user is the most important factor to be considered in AHP. Multiple inputs provided by different users can be combined and that results into a consolidated output. The AHP scale has been used to allow users to decide the importance of the criteria among each other [17].

Then the resulting judgments have been converted into a pair wise comparison matrix. At last the priorities of the elements are obtained as a result. Due to the satisfactory results provided by AHP, it has been widely used for different purposes:

1) It has been used to evaluate the consequences of different energy usage and transition pathways in UK [2].

2) It has been used to find the factors affecting the crop yield, to increase the utilization of green houses in the country [3].

3) A best access control system has been selected [4].

4) In Malaysia it has been used to determine the optimal criteria to be taken into consideration for locating the transmission line route [6].

5) It has been used for identification of the influencing parameters that must be streamlined as a policy of higher education [9].

But some limitations of AHP have been found [5]: (1) It has not been suited well for complex decision problems. (2)The hierarchy provided by it is a top down structure in which all the elements have been considered independent to each other. AHP has been extended by ANP. In addition to the AHP loops, interdependencies, feedback connections, etc., have been included in ANP [14]. The use of ANP has been increased because of these advantages over AHP. Recently it has been used for several applications:

1) It has been used to decide the order of roads, which should be repaired first [1]. 
2) It has been used for measurement of the important factors that may influence the complexity of the project [8].

3) To select the best supplier for an organization [12].

4) For selection of pilots based on some criteria [18].

5) To avoid the environmental problems and to analyze the issues related to ewaste AHP, and ANP has been used [15].

Most of the work done in the field of AHP and ANP, but to explain how to use these methods to any user or organization has always been a challenging task. The use of AHP scale has been very complicated for the user, since the user cannot be always right in prediction about which element is more useful and which is less. If the prediction of the user is wrong, then again the user is asked to supply values. Hence, an approach is required, such that the user has to supply fewer inputs and obtain ranking of options as a final output.

\section{Materials and methods}

\subsection{Criteria and data sets}

Taiwanese Food Company has been considered as an example and ANP is being applied to find the ranking of alternatives [13]. The next information is considered.

GOAL: Selecting the best advertising agency

CRITERIA:

1. Strategic planning ability $(\mathrm{C} 1)$

Subcriteria under this are:

a) Marketing research (S1)

b) Whole planning (S2)

c) Business understanding (S3)

2. Media ability (C2)

Subcriteria under this are:

d) Media planning (S4)

e) Media buying (S5)

3. Creativity (C3)

Subcriteria under this are:

f) Creative work that sells (S6)

g) Advertising awards (S7)

4. Service level (C4)

Subcriteria under this are:

h) Service range (S8)

i) Personnel quality (S9)

j) Compatibility/timing (S10)

5. Cost consciousness (C5)

ALTERNATIVES:

1. Agency A

2. Agency B

3. Agency $\mathrm{C}$

4. Agency D

5. Agency E 
2.2. Steps for computing the ranking of alternatives using ANP [14]

There are nine steps:

Step 1. Identifying the problem: Collection of data like number of objectives, criteria, subcriteria, and alternatives.

Step 2. Decomposing the problem into a tree like structure: The top most level will contain goals, second level criteria, third level subcriteria and so on, and the bottom most level will contain the alternatives.

Step 3. Node comparison: The nodes are being compared to each other as long as they are related to each other.

Step 4. Identify the complete set of clusters: The set of clusters and the elements of each cluster have been determined.

Step 5. Perform AHP: AHP has been used to evaluate the priorities of all elements.

Step 6. Non weighted super matrix construction:

a) Across top and down on the left side of the matrix, the clusters and its elements are being written alphabetically.

b) The weight of the nodes is being written as a column vector in the matrix if one cluster is influencing another.

Step 7. Weighted super matrix construction: Every node in a cluster of the initial super matrix is being multiplied by the cluster weight which is being established by pair wise comparison among the clusters.

Step 8. Limiting the super matrix construction: The weighted super matrix is being raised to powers by multiplying the super matrix by itself and the multiplication process is being halted, when all columns become equal.

Step 9. The ranking of all alternatives is obtained as a result.

\subsection{Algorithm of enhanced pair wise comparison technique}

In the existing method, AHP scale has been used, in which the user has to decide the priority of which criteria is greater as compared to other criteria. But this decision is being difficult for the user. If a wrong decision is made by the user, it will result into inconsistency. Then to supply new values, the user is being asked again. But generally the users are not being interested in providing more inputs. Therefore, a method has been suggested to reduce the number of user inputs. To calculate the weights of the elements, the next steps will be considered.

A) Use judgments about elements

Associated information about an element which is more important and which is less important for the user is being supplied as an input.

B) Pair wise comparison matrix is being constructed

The judgments are being converted into numerical values by the following rules: To compare two elements E1 and E2:

1) If $\mathrm{E} 1$ and $\mathrm{E} 2$ are equally important, then $\mathrm{E} 1=1.5, \mathrm{E} 2=1.5$

2) If $E 1$ is more important than $E 2$, then $E 1=2, E 2=1$

3) If $E 1$ is less important than $E 2$, then $E 1=1, E 2=2$

4) All the diagonal elements of the matrix will be zeroes. 
C) The numerical weight or Eigen vector is being computed by the following steps [7]:

Step 1. The sum of each column of the matrix is being computed.

Step 2. Each element of the matrix is being divided by the sum of its column.

Step 3. For each column the sum is being normalized to one.

Step 4. Average is being found across each row.

\section{Implementation}

The following data has been taken from paper [13]:

Number of clusters $=4$

Number of objectives $=1$

Number of criteria $=5$

Number of sub-criteria $=10$

Number of alternatives $=5$

The user has to make a judgment which element is more important and which is less important. Then a pair wise comparison matrix will be formed. The comparison among the criteria is shown in Table 1.After the criteria are being compared, the same procedure is applied for subcriteria to find their priorities. The subcriteria within each criterion will be compared to each other and we will obtain the results as shown in Table 2.

Table 1. Enhanced pairwise comparison among criteria (Level 2)

\begin{tabular}{|c|c|c|c|c|c|c|}
\hline Criteria & $\mathrm{C} 1$ & $\mathrm{C} 2$ & $\mathrm{C} 3$ & $\mathrm{C} 4$ & $\mathrm{C} 5$ & Eigen vector \\
\hline $\mathrm{C} 1$ & 0 & 1.0000 & 2.0000 & 1.5000 & 1.5000 & 0.2350 \\
\hline $\mathrm{C} 2$ & 2.0000 & 0 & 1.5000 & 2.0000 & 2.0000 & 0.2295 \\
\hline $\mathrm{C} 3$ & 1.0000 & 1.5000 & 0 & 2.0000 & 2.0000 & 0.2212 \\
\hline $\mathrm{C} 4$ & 1.5000 & 1.0000 & 1.0000 & 0 & 2.0000 & 0.1560 \\
\hline $\mathrm{C} 5$ & 1.5000 & 1.0000 & 1.0000 & 1.0000 & 0 & 0.1583 \\
\hline \multicolumn{7}{|c|}{$\lambda_{\max }=5.2885 ; \mathrm{CI}=0.0721 ; \mathrm{CR}=0.0644 \leqq 0.1$ consistency } \\
\hline
\end{tabular}

Table 2. Enhanced pairwise comparison among subcriteria (Level 3)

\begin{tabular}{|c|c|c|c|c|c|c|c|c|c|}
\hline \multicolumn{5}{|c|}{ For criteria $\mathrm{C} 1$} & \multicolumn{5}{|c|}{ For criteria $\mathrm{C} 4$} \\
\hline $\begin{array}{c}\text { Sub- } \\
\text { criteria }\end{array}$ & S1 & S2 & S3 & $\begin{array}{l}\text { Eigen } \\
\text { vector }\end{array}$ & & S8 & S9 & S10 & $\begin{array}{l}\text { Eigen } \\
\text { vector }\end{array}$ \\
\hline S1 & 0.000 & 2.000 & 1.000 & 0.333 & S8 & 0.000 & 1.000 & 1.000 & 0.278 \\
\hline S2 & 1.000 & 0.000 & 1.000 & 0.278 & S9 & 2.000 & 0.000 & 1.000 & 0.333 \\
\hline S3 & 2.000 & 2.000 & 0.000 & 0.389 & $\mathrm{~S} 10$ & 2.000 & 2.000 & 0.000 & 0.389 \\
\hline \multicolumn{5}{|c|}{$\lambda_{\max }=2.889 ; \mathrm{CI}=0.0556 ; \mathrm{CR}=0.096 \leqq 0.1$} & \multicolumn{5}{|c|}{$\lambda_{\max }=2.889 ; \mathrm{CI}=0.056 ; \mathrm{CR}=0.096 \leqq 0.1$} \\
\hline \multicolumn{5}{|c|}{ For criteria $\mathrm{C} 2$} & \multicolumn{5}{|c|}{ For criteria $\mathrm{C} 3$} \\
\hline & S4 & S5 & \multicolumn{2}{|c|}{ Eigen vector } & & S6 & S7 & \multicolumn{2}{|c|}{ Eigen vector } \\
\hline S4 & 0.000 & 2.000 & \multicolumn{2}{|c|}{0.500} & S6 & 0.000 & 2.000 & \multicolumn{2}{|c|}{0.500} \\
\hline S5 & 1.000 & 0.000 & \multicolumn{2}{|c|}{0.500} & S7 & 1.000 & 0.000 & \multicolumn{2}{|c|}{0.500} \\
\hline \multicolumn{5}{|c|}{$\lambda_{\max }=1.500 ; \mathrm{CI}=-0.5 ; \mathrm{CR}=-\mathrm{Inf} \leqq 0.1$} & \multicolumn{5}{|c|}{$\lambda_{\max }=1.500 ; \mathrm{CI}=-0.5 ; \mathrm{CR}=-\mathrm{Inf} \leqq 0.1$} \\
\hline
\end{tabular}


Now after the criteria and subcriteria have been compared to each other, the influence of one element on the other will be checked. That is how the other criteria are influencing criteria $\mathrm{C} 1$ and which criteria is influencing $\mathrm{C} 1$ and which is not, will be computed. Similarly for the criteria C2, C3, C4 and C5, the influence of the other elements will be computed. As a result an Eigen vector will be obtained. If an element is influencing another element, then a numerical value will be entered in the matrix; otherwise zero will be entered. For example, in Table 3, since $\mathrm{C} 1$ is not influencing itself, therefore zero is entered in the matrix. The different Eigen vectors showing the impact of the criteria on each other are shown in Table 3.

Table 3. Enhanced interdependent weights between the criteria
\begin{tabular}{|c|c|c|c|c|c|}
\hline Criteria & C1 & C 2 & C 3 & C 4 & C 5 \\
\hline C1 & 0 & 0.392 & 0.392 & 0.375 & 0.400 \\
\hline C2 & 0.400 & 0 & 0.292 & 0.416 & 0.191 \\
\hline C 3 & 0.255 & 0.292 & 0 & 0.333 & 0.255 \\
\hline C4 & 0.191 & 0.183 & 0.183 & 0 & 0.155 \\
\hline C5 & 0.155 & 0.133 & 0.133 & 0.146 & 0 \\
\hline
\end{tabular}

Similar to the criteria, the interrelationship and influence of different subcriteria on each other will be checked. S7, S8 and S10 are neither influencing any other subcriteria, nor being influenced by any subcriteria. Therefore, a zero is written as weight in the matrix. The interdependencies between the sub criteria are shown in Table 4.

Table 4. Enhanced interdependent weights between subcriteria
\begin{tabular}{|c|c|c|c|c|c|c|c|c|c|c|}
\hline Subcriteria & S1 & S2 & S 3 & S4 & S 5 & S6 & S7 & S8 & S 9 & S 10 \\
\hline S1 & 0 & 0.228 & 0.256 & 0.164 & 0 & 0.142 & 0 & 0 & 0.191 & 0 \\
\hline S2 & 0.238 & 0 & 0.107 & 0.172 & 0.280 & 0.306 & 0 & 0 & 0.128 & 0 \\
\hline S3 & 0.123 & 0.091 & 0 & 0.237 & 0.136 & 0.254 & 0 & 0 & 0.162 & 0 \\
\hline S4 & 0.194 & 0.190 & 0.107 & 0 & 0.115 & 0 & 0 & 0 & 0.100 & 0 \\
\hline S5 & 0.230 & 0.240 & 0.102 & 0 & 0 & 0 & 0 & 0 & 0.134 & 0 \\
\hline S6 & 0 & 0 & 0.110 & 0 & 0 & 0 & 0 & 0 & 0.287 & 0 \\
\hline S7 & 0 & 0 & 0 & 0 & 0 & 0 & 0 & 0 & 0 & 0 \\
\hline S8 & 0 & 0 & 0 & 0 & 0 & 0 & 0 & 0 & 0 & 0 \\
\hline S9 & 0.216 & 0.252 & 0.319 & 0.427 & 0.469 & 0.299 & 0 & 0 & 0 & 0 \\
\hline S10 & 0 & 0 & 0 & 0 & 0 & 0 & 0 & 0 & 0 & 0 \\
\hline
\end{tabular}

A partitioned matrix is being denoted as Super matrix that is also called nonweighted matrix, obtained after inserting all the obtained Eigen values into the matrix. It shows the collection of clusters, elements inside the cluster and their impact on each other. All the obtained weights are being inserted into the super matrix as sub columns. The order of the super matrix will be equal to the total number of nodes in the hierarchy. In the example that is considered, the order of the super matrix is 16 . The super matrix is shown in the Table 5 . 
Table 5. The non-weighted super matrix

\begin{tabular}{|c|c|c|c|c|c|c|c|c|c|c|c|c|c|c|c|c|}
\hline \begin{tabular}{|c|} 
Criteria/ \\
Subcriteria/ \\
Alternatives \\
\end{tabular} & Goal & $\mathrm{C} 1$ & $\mathrm{C} 2$ & C3 & $\mathrm{C} 4$ & C5 & S1 & S2 & S3 & S4 & S5 & S6 & S7 & S8 & S9 & S10 \\
\hline Goal & 0 & 0 & 0 & 0 & 0 & 0 & 0 & 0 & 0 & 0 & 0 & 0 & 0 & 0 & 0 & 0 \\
\hline $\mathrm{C} 1$ & 0.235 & 0 & 0.392 & 0.392 & 0.375 & 0.400 & 0 & 0 & 0 & 0 & 0 & 0 & 0 & 0 & 0 & 0 \\
\hline $\mathrm{C} 2$ & 0.230 & 0.400 & 0 & 0.292 & 0.146 & 0.191 & 0 & 0 & 0 & 0 & 0 & 0 & 0 & 0 & 0 & 0 \\
\hline C3 & 0.221 & 0.255 & 0.292 & 0 & 0.333 & 0.255 & 0 & 0 & 0 & 0 & 0 & 0 & 0 & 0 & 0 & 0 \\
\hline $\mathrm{C} 4$ & 0.156 & 0.191 & 0.183 & 0.183 & 0 & 0.155 & 0 & 0 & 0 & 0 & 0 & 0 & 0 & 0 & 0 & 0 \\
\hline C5 & 0.152 & 0.155 & 0.133 & 0.133 & 0.146 & 0 & 0 & 0 & 0 & 0 & 0 & 0 & 0 & 0 & 0 & 0 \\
\hline S1 & 0 & 0.333 & 0 & 0 & 0 & 0 & 0 & 0.228 & 0.256 & 0.164 & 0 & 0.142 & 0 & 0 & 0.191 & 0 \\
\hline S2 & 0 & 0.278 & 0 & 0 & 0 & 0 & 0.238 & 0 & 0.107 & 0.172 & 0.280 & 0.306 & 0 & 0 & 0.128 & 0 \\
\hline S3 & 0 & 0.389 & 0 & 0 & 0 & 0 & 0.123 & 0.091 & 0 & 0.237 & 0.136 & 0.254 & 0 & 0 & 0.162 & 0 \\
\hline S4 & 0 & 0 & 0.500 & 0 & 0 & 0 & 0.194 & 0.190 & 0.107 & 0 & 0.115 & 0 & 0 & 0 & 0.100 & 0 \\
\hline S5 & 0 & 0 & 0.500 & 0 & 0 & 0 & 0.230 & 0.240 & 0.102 & 0 & 0 & 0 & 0 & 0 & 0.134 & 0 \\
\hline S6 & 0 & 0 & 0 & 0.500 & 0 & 0 & 0 & 0 & 0.110 & 0 & 0 & 0 & 0 & 0 & 0.287 & 0 \\
\hline S7 & 0 & 0 & 0 & 0.500 & 0 & 0 & 0 & 0 & 0 & 0 & 0 & 0 & 0 & 0 & 0 & 0 \\
\hline S8 & 0 & 0 & 0 & 0 & 0.278 & 0 & 0 & 0 & 0 & 0 & 0 & 0 & 0 & 0 & 0 & 0 \\
\hline S9 & 0 & 0 & 0 & 0 & 0.333 & 0 & 0.216 & 0.252 & 0.319 & 0.427 & 0.469 & 0.299 & 0 & 0 & 0 & 0 \\
\hline $\mathrm{S} 10$ & 0 & 0 & 0 & 0 & 0.389 & 0 & 0 & 0 & 0 & 0 & 0 & 0 & 0 & 0 & 0 & 0 \\
\hline A & 0 & 0 & 0 & 0 & 0 & 0 & $0.227 \mid$ & 0.249 & 0.214 & 0.250 & 0.239 & 0.249 & 0.249 & 0.249 & 0.249 & 0.184 \\
\hline B & 0 & 0 & 0 & 0 & 0 & 0 & 0.146 & 0.163 & 0.146 & 0.165 & 0.148 & 0.213 & 0.213 & 0.163 & 0.213 & 0.183 \\
\hline C & 0 & 0 & 0 & 0 & 0 & 0 & 0.201 & 0.186 & 0.199 & 0.173 & 0.185 & 0.186 & 0.186 & 0.185 & 0.186 & 0.220 \\
\hline D & 0 & 0 & 0 & 0 & 0 & 0 & 0.213 & 0.211 & 0.226 & 0.211 & 0.215 & 0.186 & 0.186 & 0.211 & 0.186 & 0.202 \\
\hline E & 0 & 0 & 0 & 0 & 0 & 0 & 0.212 & 0.212 & 0.191 & 0.214 & 0.202 & 0.213 & 0.166 & 0.190 & 0.166 & 0.212 \\
\hline
\end{tabular}

Then it is checked if the super matrix weather sum of all columns is equal to one or not. If this condition is satisfied, then the weighted and non-weighted super matrix will be the same. If it is not one, then the weighted super matrix is being computed. Then a limiting matrix is being computed and the values for the alternatives obtained are $0.030(\mathrm{~A}), 0.022(\mathrm{~B}), 0.024$ (C), $0.026(\mathrm{D})$, and 0.023 (E).

\section{Results and discussion}

A sample data set of ANP has been considered [13] and both methods have been applied. After applying this approach, the comparison of the Eigen vectors obtained by two methods is shown in Table 6 and the comparison of ranking the agencies by an existing ANP [13] and enhanced ANP obtained are shown in Table 7 below given. The weights are compared and it is obtained that the result of ranking the criteria by both methods is the same. Besides, in case of subcriteria there is one rank difference in the enhanced method. The result obtained by the new method has one rank difference for every alternative like in the case of agencies $\mathrm{C}$ and $\mathrm{D}$. The rank of $\mathrm{C}$ is 2 in the existing method but it is 3 in the enhanced method. The most preferable option obtained by both methods is the same as agency A as shown in Table 7. Hence, the proposed method is providing consistent results. 
Table 6. Eigen vector comparison

\begin{tabular}{|cc|c|c|}
\hline \multirow{6}{*}{ For criteria/for subcriteria } & $\begin{array}{c}\text { Saaty's pairwise comparison } \\
\text { technique }\end{array}$ & $\begin{array}{c}\text { Enhanced pair wise } \\
\text { comparison technique }\end{array}$ \\
\hline \multirow{6}{*}{ For criteria } & C1 & 0.422 & 0.235 \\
& C2 & 0.107 & 0.230 \\
& C3 & 0.293 & 0.221 \\
& C4 & 0.091 & 0.156 \\
C5 & 0.087 & 0.158 \\
\hline \multirow{6}{*}{ For subcriteria } & S1 & 0.328 & 0.333 \\
& S2 & 0.310 & 0.278 \\
& S3 & 0.362 & 0.389 \\
& S4 & 0.572 & 0.500 \\
& S5 & 0.428 & 0.500 \\
& S7 & 0.790 & 0.500 \\
& S8 & 0.210 & 0.500 \\
& S9 & 0.138 & 0.278 \\
S10 & 0.350 & 0.333 \\
& & 0.512 & 0.389 \\
\hline
\end{tabular}

Table 7. Comparison of results

\begin{tabular}{|c|c|c|c|c|}
\hline Alternatives & $\begin{array}{c}\text { Existing } \\
\text { ANP }\end{array}$ & Ranking & $\begin{array}{c}\text { Extended } \\
\text { ANP }\end{array}$ & Ranking \\
\hline Agency A & 0.333 & 1 & 0.030 & 1 \\
\hline Agency B & 0.097 & 4 & 0.022 & 5 \\
\hline Agency C & 0.252 & 2 & 0.024 & 3 \\
\hline Agency D & 0.233 & 3 & 0.026 & 2 \\
\hline Agency E & 0.085 & 5 & 0.023 & 4 \\
\hline
\end{tabular}

\section{Conclusion}

A mathematical technique called Multi Criteria Decision Making (MCDM) is said to be a sub-field of operational research. It has many applications like sorting, classification, prediction and providing ordering of options, from the most preferred to the least preferred. Different ways have been provided for different options to achieve the objectives, since no option is best in achieving the objectives. Multiple conflicting criteria are available in our daily life that require to be evaluated for making decisions. Among the approaches suggested for MCDM, none is suitable for all the fields. The use of AHP scale is complicated and the user has to give more inputs. The study presented a new method for constructing pair wise comparison matrices, such that the number of user inputs is reduced. The proposed method has replaced the AHP scale and allows the user to say which element is more or less important without specifying to what extent it is more or less preferable. A sample data set [13] has been taken as an example to decide the best agency for advertisement. By comparing the existing ANP method and the improved ANP method, it is found that the proposed method provides $80 \%$ accuracy in Eigen vector calculation. In case of enhanced ANP, the ranking of alternatives differs by 
one rank. Finally, alternative 1 that is agency A has proved as the best option by both the methods. Ranking of the alternatives obtained as: agency A (0.030), agency B (0.022), agency C (0.024), agency D (0.026), and agency $\mathrm{E}(0.023)$.Hence, the proposed method provides an efficient way to find the ranking of alternatives and reduces the user inputs. Further on it can be used for classification, prediction and sorting.

\section{References}

1. Agustiansyah, R., N. A m b ars ari. Implementation of Analytic Network Process (ANP) and Analytical Hierarchy Process (AHP) Method to Determine Priorities of Roads to be Repaired at Bogor City Department of Public Works. - In: International Conference of Information and Communication Technology (IColCT), 2013, IEEE, 978-1-4673-499, pp. 13-25.

2. Toossi, A., F. C a m c i, L. V arga. Developing an AHP Based Decision Model for Energy Systems Policy Making, 2013. IEEE, 978-1-4673-4569, pp. 9-13.

3. Q i a n, G., X i a n g-d ong W an g. Greenhouse Parameter Control Strategy Based on the AHP (Analytical Hierarchy Process), 2013. IEEE, 978-1-4673-5534, pp. 6-13.

4. A zha r, A., M. A m in, M. N a u man, S. U. S hah. Efficient Selection of Access Control Systems through Multi Criteria Analytical Hierarchy Process, 2012. IEEE, 978-1-4673-4451, pp. 7-12.

5. G o e p e 1, K. D. AHP and ANP Application, 2011 http://bpmsg.com/wpcontent/uploads/2011/07/BPMSG_AHP_ANP.pdf

6. Hu s a i n, F., N. A. S u la i m a n, K. A. H a s h i m, A. M. S a m a d. Multi-Criteria Selection for TNB Transmission Line Route Using AHP and GIS. - In: International Conference on System Engineering and Technology, 11-12 September 2012, IEEE, Bandung, Indonesia, 978-1-4673-2376, pp. 5-12.

7. L i n, C.-T., P.-F. H s u. Selection of Internet Advertising Networks Using an Analytic Hierarchy Process and Grey Relational Analysis. - Information and Management Sciences, Vol. 14, 2003, No 2, pp. 1-16.

8. H e, Q-h., L. L u o, J. W a n g, Y-k L i, L. Z h a o. Using Analytic Network Process to Analyze Influencing Factors of Project Complexity. - In: 19th International Conference on Management Science \& Engineering, 20-22 September 2012, IEEE, Dallas, USA, 978-1-4673-3014, pp. 5-12.

9. D e y, B., J. M e h e d i, R. D e y. Assessment of Ph.D (Technology) Quality in Indian Universities: AHP Based Decision Model. - In: IEEE International Conference on Teaching, Assessment and Learning for Engineering (TALE), 2013, Bali Dynasty Resort, Kuta, Indonesia, 978-1-4673-6355, pp. 6-13.

10. Habiba, U m m-e., S. A s g h a r. A Survey on Multi-Criteria Decision Making Approaches. In: International Conference on Emerging Technologies, 2009, 978-1-4244-5632, pp. 1-9.

11. Ozdemir, Y., H. B a sligil, M. Karaca. Aircraft Selection Using Analytic Network Process: A Case for Turkish Airlines. - In: Proc. of World Congress on Engineering, Vol. II WCE, 6-8 July 2011, London, UK.

12. S adeghi, M., M. A. Rashidzadeh, M. A. S oukhakian. Using Analytic Network Process in a Group Decision-Making for Supplier Selection. - Informatica, Vol. 23, 2012, No 4, Vilnius University, pp. 621-643.

13. H s u, P.-F., M.-H. Ku o. Applying the ANP Model for Selecting the Optimal Full-Service Advertising Agency. - International Journal of Operations Research, Vol. 8, 2011, No 4, pp. $48-58$.

14. D a ğ d e v i r e n, M., İ. Y ü k s e l. Personnel Selection Using Analytic Network Process. İstanbul Ticaret Üniversitesi Fen Bilimleri Dergisi Y11: 6 Say1: 11 Bahar, 2007/1 s., pp. 99-118.

15. Jo, H., S. Y ang, T. Kim, H. Kim. ANP-Based Reverse Logistics Model for e-Waste Management. - In: POMS 21st Annual Conference, Vancouver, Canada, 7-10 May 2010. 
16. Chicco, G., A. Mazza, A. Russ o. Optimization and Decision-Making in Electrical Distribution Networks. - In: 2012 International Conference and Exposition on Electrical and Power Engineering (EPE’2012), 25-27 October 2003, Iasi, Romania.

17. H a a s, R., O. M e i x n e r. Analytical Hierarchy Process.

http://www.boku.ac.at/mi/ahp/ahptutorial.pdf

18. Y a z g a n, E., A. K. U s t u n. Application of Analytical Network Process: Weighting of Selection Criteria for Civil Pilots. - Journal of Aeronautics and Space Technologies, Vol. 5, July 2011, No 2, pp. 1-12. 